\section{The Brazilian version of the Quality of Life Assessment of Growth Hormone Deficiency in Adults (QoL-AGHDA) - Four-stage translation and validation}

\author{
Versão brasileira do questionário "Quality of Life - Assessment \\ of Growth Hormone Deficiency in Adults" (QoL-AGHDA) - Tradução \\ e validação em quatro estágios
}

Antônio Ribeiro-Oliveira Jr. ${ }^{*}$, Suélem Simão Mol ${ }^{{ }^{*}}$, James Twiss², Guilherme Asmar Alencar ${ }^{1}$, Paulo Augusto Carvalho Miranda ${ }^{3}$, Luciana A. Naves ${ }^{4}$, Monalisa F. Azevedo ${ }^{4}$, Flávia M. A. Basílio ${ }^{5}$, César Luiz Boguszewski ${ }^{5}$, Kátia C. Nogueira ${ }^{6}$, Lúcio Vilar7, Maria Koltowska-Haggstrom ${ }^{8}$, Steve P. McKenna ${ }^{2}$

\begin{abstract}
Objective: This study reports on the Brazilian Portuguese adaptation of the QoL-AGHDA (Quality of Life Assessment of Growth Hormone Deficiency in Adults) for use in adult growth hormone deficient (GHD) patients. Materials and methods: The translation process adopted the dual panel methodology. The questionnaire was tested through field-test interviews (16 GHD patients). In the final stage, data from $120 \mathrm{GHD}$ patients (81 included in a test-retest analysis) were analyzed for internal consistency, test-retest reliability, convergent validity and validity among known groups. Results: The translation panels were successful and the draft version was amended to improve the wording as a result of the field-test interviews. Cronbach's alpha was 0.90 and test-retest reliability 0.88 . QoL-AGHDA scores had the expected pattern of association with NHP scale scores and QoL-AGHDA was able to differentiate significantly between patients based on patient-reported general health $(p<0.01)$ and $\mathrm{QoL}(\mathrm{p}<0.01)$. Conclusions: The adaptation of the QoL-AGHDA for a Brazilian population was successful and the adapted questionnaire was shown to be reliable and valid. Arq Bras Endocrinol Metab. 2010;54(9):833-41
\end{abstract}

\section{Keywords}

Growth hormone; quality of life; treatment outcomes; QoL-AGHDA

\section{RESUMO}

Objetivo: Este estudo relata o processo de adaptação da versão brasileira do questionário QoL-AGHDA (Quality of Life - Assessment of Growth Hormone Deficiency in Adults) para pacientes com deficiência do hormônio de crescimento (DGH). Materiais e métodos: A tradução adotou a metodologia de duplo painel. 0 questionário foi testado por intermédio de entrevistas direcionadas com 16 pacientes com DGH. No estágio final, dados de 120 pacientes com DGH (81 com teste/reteste) foram analisados para consistência interna, confiabilidade teste/reteste, validade convergente e validade entre grupos conhecidos. Resultados: Os grupos de tradução foram bem-sucedidos e a versão final foi adaptada seguindo sugestões obtidas das entrevistas com os 16 pacientes. 0 coeficiente alfa de Cronbach foi 0,90 , confiabilidade teste/reteste 0,88 , escores QoL-AGHDA se correlacionaram com o NHP $(p<0,01)$ e também com a saúde geral relatada pelos pacientes $(p<0,01)$. Conclusões: A adaptação do QoL-AGHDA para a população brasileira foi bem-sucedida, e a nova versão demonstrou ser válida e confiável. Arq Bras Endocrinol Metab. 2010;54(9):833-41

Descritores

Hormônio do crescimento; qualidade de vida; terapêutica; QoL-AGHDA

\author{
* These should be considered \\ as joint authors \\ 1 Universidade Federal de \\ Minas Gerais (UFMG), Belo \\ Horizonte, MG, Brazil \\ ${ }^{2}$ Galen Research Ltd, \\ Manchester/UK \\ ${ }^{3}$ Santa Casa de Minas Gerais \\ Belo Horizonte, MG, Brazil \\ ${ }^{4}$ Universidade de Brasília \\ (UnB), DF, Brasília, Brazil \\ ${ }^{5}$ Serviço de Endocrinologia \\ e Metabologia (SEMPR), \\ Universidade Federal do Paraná \\ (UFPR), Curitiba, PR, Brazil \\ ${ }^{6}$ Hospital do Brigadeiro, \\ São Paulo, SP, Brazil \\ 7 Universidade Federal \\ de Pernambuco (UFPE), \\ Recife, PE, Brazil \\ ${ }^{8}$ KIMS Medical Outcomes, Pfizer \\ Endocrine Care, Sollentuna/Sweden
}

Correspondence to: Antônio Ribeiro-Oliveira Jr. Rua São Romão, 343/701 30330-120 - Belo Horizonte, MG, Brazil

brolivei@uol.com.br/antoniorojr@ gmail.com

Received on Sept/16/2010 Accepted on Nov/1/2010 


\section{INTRODUCTION}

rowth hormone deficiency (GHD) in adults is $\mathbf{J}_{\text {associated with decreased lean body mass tissue }}$ $(1,2)$ and bone density $(3)$, increased abdominal body fat (4), functional impairment (5) and a number of cardiovascular risk factors (6-8). It impacts on patients' quality of life (QoL) in a number of ways, resulting from increased levels of fatigue (9), social isolation (10), anxiety (11) and poor memory (12). GH replacement therapy has been shown to improve various abnormalities associated with GHD (13-15), including QoL, which has been used in some centers as the most compelling reason for initiating GH therapy (16-22). The main measure of QoL in adult GHD is the Quality of Life Assessment of Growth Hormone Deficiency in Adults (QoL-AGHDA) $(23,24)$.

The QoL-AGHDA was first developed in the United Kingdom and has since been adapted for use in several additional languages (24). It adopts the needs-based model of QoL outlined by Hunt and McKenna in 1992 (25). This model postulates that life gains its quality from the ability of individuals to satisfy his/her needs. It is assumed that QoL is low when few needs are fulfilled. In this context, poor health interferes - in most cases adversely - with satisfaction of needs and, consequently, has a negative impact on QoL. In the UK, the National Institute for Clinical Excellence requires patients to complete the QoL-AGHDA in order to determine whether they should receive $\mathrm{GH}$ replacement (26).

In Brazil, there are established guidelines to help clinicians judge those adults with GHD that should receive GH replacement. However, QoL is not part of the protocol-based therapeutic decision (27). The establishment of a validated GHD-specific measure of QoL for guiding such decisions in Brazil would be of great benefit. This approach would ultimately permit a more rational use of this high cost prolonged treatment, as adopted in other countries (26). In addition, with increasing globalization, cross-cultural communication and the high number of international clinical trials, culturally equivalent outcome instruments available in different languages are crucial. Each language version must be culturally relevant and acceptable to the target population and must also be psychometrically comparable.

The aim of this study was to produce a Brazilian Portuguese adaptation of the QoL-AGHDA that is conceptually equivalent to the UK-English version.

\section{MATERIAL AND METHODS}

Content of the QoL-AGHDA was generated from in-depth qualitative interviews conducted with adult patients with GHD in the UK. The measure contains 25 items that require yes/no answers. Its score is computed by summing the number of "yes" answers with high QoL-AGHDA scores indicating poor QoL. Questionnaires containing more than $20 \%$ missing responses are excluded from analyses (24).

Five language versions (English, Swedish, German, Italian, and Spanish) were developed simultaneously using dual translation panels $(23,24)$. Versions for the United States, Belgium, Netherlands, Denmark, Poland, Serbia, the Czech Republic and Slovakia were developed later.

The translation process adopted the dual panel methodology recommended by Hunt and cols. $(25,28)$. In the dual panel method quality is ensured by processes built in during each step of translation rather than being checked a posteriori. This methodology has been used in the development of all language adaptations of the QoL-AGHDA. It emphasizes the importance of achieving conceptual equivalence of translated items to the original. This allows the comparison of QoL-AGHDA scores across countries.

The dual-panel translation and validation methodology consists of 4 stages: Stage 1: bilingual translation panel - to provide the initial translation into the target language; Stage 2: lay translation panel - where items are assessed for comprehension and "naturalness" of language; Stage 3: field-testing for face and content validity-performed in a small group of the target audience (patients); Stage 4: assessment of psychometric and scaling properties.

\section{Bilingual panel (Stage 1)}

The bilingual panel was conducted at the Clinics Hospital of Federal University of Minas Gerais/Brazil and included eight Brazilians bilingual in Portuguese and English. All participants had Brazilian Portuguese as their primary language. The purpose of this panel was to translate the instructions, items and response categories to the target language. The panel coordinator was a Professor of Medicine who represented the local investigator (AROJr) and his role was to ensure that no panel member was too dominant and to help find consensus on the appropriate translations. This meeting was also attended by one of the original developers of 
the QoL-AGHDA (SPM), whose role was to guide the process and, when needed, to explain the conceptual meaning of the items to panel members.

The panel worked together as a team on the translation of the QoL-AGHDA, aimed at finding the best form of words that could represent the original UK English instructions and items. Panel members were informed of the purpose of the panel and received a brief description of GHD in adults, the effects of the disease on QoL and the way in which the QoL-AGHDA is used in the evaluation of QoL in GHD patients. Panel members received the English version of the instrument a week before the translation panel meeting and they were asked to read it through with a view to translating, with the following requirements in mind; to capture the same concepts as the English questionnaire and to produce a comprehensible and acceptable formulation of the concept. At the meeting items were presented to the group one-by-one and their meaning explained.

\section{Lay panel (Stage 2)}

The translations produced by the bilingual panel were considered by a group of nine Brazilians of an average to lower than average educational level, who were considered to be more typical of the target population. The lay panel was conducted at the Clinics Hospital of Federal University of Minas Gerais, Brazil. None of the participants could speak English. All were physically active and lived in the State of Minas Gerais. The purpose of this second panel was to ensure that the final wording of the items was appropriate to the patients.

Participants were presented with the translations made by the bilingual panel and asked to comment on them in terms of comprehension and acceptability. In particular, they were asked to decide whether the phrasing and language was acceptable or whether these should be changed to make the items more "natural", while maintaining the original meaning. Again, the panel worked as a group to decide on the most appropriate wording. This panel had priority over the bilingual panel. GHD patients were excluded from the lay panel as its purpose was to determine the most appropriate wording for the questionnaire, rather than to comment on the appropriateness of the items.

The participants of this panel worked solely with the target language version of the questionnaire (Brazilian Portuguese). It was the role of the leader (who had also been the leader of the bilingual panel) to ensure that the original meaning was maintained in the final translation.

\section{Procedure for Field Test Interviews (Stage 3)}

The purpose of the interviews was to test the applicability, comprehension, relevance and comprehensiveness of the new instrument with relevant respondents. The interviews took the form of one-to-one semi-structured interviews with adult GHD patients.

Patients were recruited from the Department of Internal Medicine (Endocrinology Centre), Federal University of Minas Gerais, Belo Horizonte. No patient had received GH therapy in the previous six months.

Respondents were asked to complete the questionnaire in the presence of an interviewer, who made a note of any obvious difficulties or hesitation over particular items. Interviewees were then asked to comment on the questionnaire items, instructions and response format. Specifically, respondents were asked whether they thought the items were relevant, applicable and comprehensible and if they thought any important aspects of their experience of GHD had been omitted. Once their spontaneous views had been elicited, interviewees were asked specific questions about items that had been highlighted a priori as requiring discussion. These were alternative wordings for the same or similar concepts or items that were seen as being potentially problematic for some or all respondents.

\section{Procedure for psychometric validation (Stage 4)}

The data needed to establish the psychometric properties of the new version of the QoL-AGHDA were collected from patients with GHD. The QoL-AGHDA was administered via postal survey on two occasions (Times 1 and 2), with 15 days between administrations. Participants also completed the Nottingham Health Profile questionnaire (NHP) (29). The NHP is a generic instrument, designed to measure subjective health status in the following sections; physical mobility, pain, sleep, emotional reactions, social isolation, and energy level. The NHP score is presented as a profile (scores per individual domains as described above). An index of distress can also be calculated (NHP-Distress) based on responses to 24 of the items (30).

At the first assessment patients also answered demographic questions (gender, age, marital status, employment) and rated their general health and QoL.

One hundred and twenty GHD patients were recruited from 6 different Brazilian endocrine centers. From the 120 patients enrolled to this stage of validation from December 2007 to October 2009, 59 were from the Federal University of Minas Gerais, Belo Ho- 
rizonte (MG), 19 were from Hospital Santa Casa, Belo Horizonte (MG), 19 from the University of Brasília/ Brasília (DF), 10 from the Federal University of Pernambuco/Recife (PE), 7 from SEMPR, the Federal University of Paraná/Curitiba (PR), and 6 from Hospital Brigadeiro/São Paulo (SP).

The hypopituitary patients selected were all on stable pituitary hormone replacement for any pituitary deficit, excluding $\mathrm{GH}$, in the previous six months. Post-menopausal women were not receiving sex steroid replacement. Patients with visual impairments compromising reading abilities were excluded from the study. Responses to the completed questionnaires were entered into an electronic database.

The $4^{\text {Th }}$ stage of the validation process encompassed:

\section{Internal consistency}

Internal consistency was assessed using Cronbach's alpha coefficients $(31,32)$. Alpha measures the extent to which items in a scale are inter-related. An alpha below 0.7 indicates that the items do not work together to form a scale.

\section{Test-retest reliability}

The test-retest reliability of a measure is an estimate of its reproducibility over time when no change in condition has taken place. It is assessed by correlating scores on the scales obtained on two different occasions. A high correlation (Spearman rank correlation coefficient) indicates that the instrument produces low random measurement error. A minimum value of 0.85 is required where a measure is intended to be used on an individual basis (33).

\section{Convergent validity}

Convergent validity can be determined by assessing the level of association between scores on one scale and those on a comparator scale that measures the same or a related construct. For the present investigation, the NHP was used as a comparator instrument. QoL-AGHDA scores were correlated with NHP section scores using Spearman rank correlation coefficients.

\section{Known groups validity}

Known groups validity can be assessed by testing the ability of a measure to distinguish between groups of people that differ according to some known factor. The factors used for the present investigation were patient- -reported general health (excellent, good, fair, poor, very poor) and patient-reported QoL (excellent, good, fair, poor, very poor).

\section{Statistical analysis}

Results were expressed as means $\pm \mathrm{SD}$ and/or medians (IRQ). Non-parametric statistical tests (Spearman Rank correlations, Mann-Whitney U Tests for two groups or Kruskal-Wallis One-Way Analysis of Variance for three or more groups) were employed throughout the analyses due to the ordinal nature of the data. All statistical analyses were conducted using the SPSS version 16 with $\mathrm{p}<0.05$ taken to indicate statistical significance.

\section{Ethics}

The study was approved by the Brazilian National Ethics Committee - Comitê Nacional de Ética em Pesquisa (Conep) and by the Local Ethics Committees from each participating institution. All the participants gave informed consent.

\section{RESULTS}

\section{Bilingual panel (Stage 1)}

Participant details are provided in table 1 . All participants in the bilingual panel had received a university education.

It was not always possible to find a "natural" translation for an item in the new language. Where this was the case, it was necessary to find a phrase that was conceptually equivalent. It was also vital that new items were expressed in common (everyday) language in order to appeal to respondents. The panel worked together to agree on the most appropriate translation. The group had the opportunity to discuss alternatives and the final decision on translations was taken by the group rather than a single researcher.

Two items required considerable discussion before the panel came to a conclusion on the most appropriate wording. The first, I have to read things several times before they sink in was expressed in terms of difficulty for the person to get an idea into their head rather than being directly related to memory - Eu tenho de ler as coisas várias vezes para conseguir gravá-las.

The second item was I find it hard to mix with people. Difficulty was found with this item as it is unusual for people to be lonely in Brazil as compared to European countries. It was translated in a way that gives 
the impression that is hard to have a good relationship with others in daily life - Eu acho difícil conviver com as outras pessoas. It was not found necessary to send alternative versions of any item or instruction for consideration by the subsequent lay panel.

The meeting lasted just over two hours.

\section{Lay panel (Stage 2)}

Participant details are shown in table 1 . All participants in the lay panel had an average to below average education level.

Participants worked together to improve the structuring of some of the translations suggested by the bilingual panel. However, only minor changes needed to be made before the questionnaire was ready for field-testing.

The lay panel lasted one hour and forty-five minutes.

\section{Cognitive debriefing interviews (Stage 3)}

Participant details are shown in table 1 .

Table 1. Bilingual panel, lay panel and cognitive debriefing demographic details

\begin{tabular}{lccc}
\hline & Bilingual panel & Lay panel & $\begin{array}{c}\text { Cognitive } \\
\text { debriefing }\end{array}$ \\
\hline $\mathrm{n}$ & 8 & 9 & 16 \\
Gender & & & \\
$\quad$ Male (\%) & $4(50.0 \%)$ & $3(33.3 \%)$ & $9(56.3 \%)$ \\
Age (years) & & & \\
$\quad$ Mean (SD) & $30.4(5.1)$ & $42.6(13.7)$ & $47.1(20.6)$ \\
Median (IQR) & $28.5(27.0-34.8)$ & $45.0(28.5-53.5)$ & $49.0(25.8-71.3)$ \\
Range & $25-40$ & $23-62$ & $20-75$ \\
\hline
\end{tabular}

SD: standard deviation; IQR: inter-quartile range.

In total, 16 adult GHD patients were interviewed by the authors (AROJr, SSM and GAA) at the Federal University of Minas Gerais in the first semester of 2007. All these patients had low age-adjusted insulin-like growth factor-1 (IGF-1) coupled to two or more pituitary deficits (14). None of them had any neurological deficit that could compromise understanding or reading ability of the questionnaire. The interviews took place in a quiet room at the Endocrinology centre.

All interviewees were clear about the purpose of the interview and read the instructions before starting to complete the measure. None of the respondents failed to understand the instructions, none of the questions were deemed inappropriate and none of the interviewees reported that important aspects of their experience had been omitted from the questionnaire.
Overall the measure was well accepted by interviewees. Some small changes were suggested to improve wording. For example Eu (I) was added to many of the items in order to stress the importance of the participants' own views. In addition, alternative endings were provided for pronouns and adjectives to cater for the gender of the respondent. Each interview lasted a mean of $20 \pm 4$ minutes. In addition, some patients expressed a desire for a 'sometimes' option. In these cases, participants were reminded that the instructions asked them to consider how they feel at the moment. A few patients skipped some questions and returned to them later.

One specific item caused concern for several interviewees - Eu tenho de me obrigar a fazer tudo aquilo que preciso (I have to push myself to do things). The idea of obliging oneself suggested by the panels was found to be difficult to understand by some interviewees. The item was changed to Eu tenho de me esforçar para fazer tudo o que preciso which equates to 'I have to make strong efforts to do my own tasks'.

Sample items from the final version of the QoL-AGHDA in Brazilian Portuguese are shown in Appendix 1.

\section{Psychometric validation (Stage 4)}

\section{Descriptive statistics}

The demographic and disease information for the survey participants is shown in table 2. Approximately $60 \%$ of the sample was female. The mean age was 46.3 (range $=18-85)$ years, with over half married or living as married. The educational level was low - a third of respondents had gone to university. All of them had low age-adjusted IGF-1 levels coupled to two or more pituitary deficits, or $\mathrm{GH}$ after an insulin tolerance test lower than $3 \mu \mathrm{g} / \mathrm{L}$ (14). None of them had any important neurological deficit that could compromise understanding or reading ability of the questionnaire.

Out of the 120 patients, $79(65.8 \%)$ had undergone pituitary surgery. Thirty-six were from non-secreting adenomas (45.6\%), 14 craniopharyngiomas (17.7\%), 12 prolactin-secreting adenomas (15.2\%), 5 ACTH secreting-adenomas $(6.3 \%)$, and 12 from other causes (ependimoma, meningioma, apoplexy, arachnoid cyst, trauma, sarcoidosis) (15.2\%). These numbers are similar to those reported in the literature, where non-secreting pituitary macroadenomas and craniopharyngiomas are found to be the most prevalent causes of pituitary 
Table 2. Demographic and disease information for patients participating in the psychometric validation (stage four)

\begin{tabular}{|c|c|}
\hline \multicolumn{2}{|l|}{ Gender } \\
\hline Male (\%) & $46(38.3)$ \\
\hline Female (\%) & $72(60.0)$ \\
\hline Missing (\%) & $2(1.7)$ \\
\hline \multicolumn{2}{|l|}{ Age (years) } \\
\hline Mean (SD) & $46.3(15.2)$ \\
\hline Range & $18-85$ \\
\hline \multicolumn{2}{|l|}{ Educational level (\%) } \\
\hline Primary (5-10/11 years) & $47(39.2)$ \\
\hline Secondary (11-15/16 years) & $31(25.8)$ \\
\hline Sixth-Form (16-18 years) & $30(25.0)$ \\
\hline University & $6(5.0)$ \\
\hline Postgraduate & $4(3.3)$ \\
\hline Missing & $2(1.7 \%)$ \\
\hline \multicolumn{2}{|l|}{ Marital status (\%) } \\
\hline Married/Living as Married & $69(57.5)$ \\
\hline Widowed & $3(2.5)$ \\
\hline Divorced/separated & $8(6.7)$ \\
\hline Single & $38(31.7)$ \\
\hline Missing & $2(1.7 \%)$ \\
\hline \multicolumn{2}{|l|}{ Duration of GHD (years) } \\
\hline Mean (SD) & $11.8(10.7)$ \\
\hline Range & $1-40$ \\
\hline \multicolumn{2}{|l|}{ Self-reported health (\%) } \\
\hline Excellent & $11(9.2)$ \\
\hline Good & $46(38.3)$ \\
\hline Fair & $54(45.0)$ \\
\hline Poor & $6(5.0)$ \\
\hline Very poor & $1(0.8)$ \\
\hline Missing & $2(1.7 \%)$ \\
\hline \multicolumn{2}{|l|}{ Overall QoL (\%) } \\
\hline Excellent & $17(14.2)$ \\
\hline Good & $48(40.0)$ \\
\hline Fair & $46(38.3)$ \\
\hline Poor & $7(5.8)$ \\
\hline Very poor & 0 \\
\hline Missing & $2(1.7 \%)$ \\
\hline
\end{tabular}

GHD: growth hormone deficiency; SD: standard deviation; QoL: quality of life.

surgery and morbidity $(34,35)$. Twenty-six $(32.9 \%)$ of these patients had also undergone radiotherapy. Of those patients who had not had surgery, 23 (56.1\%) had GHD due to Sheehan syndrome, followed by idiopathic childhood-onset GHD.

Concerning pituitary deficits, $8.3 \%$ (10 patients) had only GH deficiency, 15.8\% (19 patients) had 2 pituitary deficits, $13.3 \%$ (16 patients) had 3 pituitary deficits, and the remainder $62.5 \%$ (75 patients) had panhypopituitarism. Thirteen out of those 75 panhypopituitary patients (17.3\%) also had diabetes insipidus. This is also similar to what has been reported in the literature for other GHD populations (36-38).

Eighty-one individuals (67.5\%) completed the questionnaire on both occasions. The low completion rate at Time 2 was because the study was stopped when a sufficient sized sample for test-retest purposes was achieved. The subgroup that did not complete the measure at the second time point did not differ significantly from the rest of the sample in terms of age, gender or Time 1 QoL-AGHDA score.

Table 3 shows QoL-AGHDA scores at Times 1 and 2 . Minimal levels of ceiling and floor effects were found indicating that the items were well targeted to the sample. In addition, the score distributions at the item level were good, with no items attracting all 'true' or all 'untrue' responses.

Table 3. QoL AGHDA descriptive statistics

\begin{tabular}{lcccccc}
\hline QoL-AGHDA & $\mathbf{n}$ & $\begin{array}{c}\text { Median } \\
\text { (IQR) }\end{array}$ & $\begin{array}{c}\text { Mean } \\
\text { (SD) }\end{array}$ & Range & $\begin{array}{c}\text { Scoring } \\
\min (\%)\end{array}$ & $\begin{array}{c}\text { Scoring } \\
\max (\%)\end{array}$ \\
\hline Time 1 & 120 & $\begin{array}{c}11.0 \\
(6.0-17.8)\end{array}$ & $\begin{array}{l}11.8 \\
(6.7)\end{array}$ & $0.0-25.0$ & 2.5 & 2.5 \\
Time 2 & 81 & $\begin{array}{c}12.0 \\
(6.0-19.0)\end{array}$ & $\begin{array}{c}12.3 \\
(7.2)\end{array}$ & $0.0-25.0$ & 2.5 & 1.2 \\
& & & & \\
\hline
\end{tabular}

SD: standard deviation; IQR: inter-quartile range.

\section{Internal consistency}

The Cronbach's alpha coefficients for internal consistency were 0.90 and 0.92 for Times 1 and 2. This shows that the instrument had good inter-relatedness of items. In addition, all of the CITCs at Time 1 were between 0.2 and 0.8 , indicating that no items were unrelated to or redundant within the scale. At Time 2 two items had ITCs below 0.2. As this occurred at only one time point these items were not considered problematic. The statistics also showed that the removal of any individual item would not have increased the overall alpha coefficient of the scale at either time point.

\section{Test-retest reliability}

The test-retest reliability for the QoL-AGHDA was 0.88 , indicating that the scale produces low levels of random measurement error. This in turn suggests that the measure has good reproducibility. 


\section{Convergent validity}

Table 4 shows the correlations between scores on the QoL-AGHDA and those on the NHP. As expected, the QoL-AGHDA correlated higher with the Energy level, Emotional reactions and Social isolation sections, confirming findings from other studies (24). There were low correlations between the QoL-AGHDA and the Pain and Sleep scales. In addition, the QoL-AGHDA had a moderately high correlation with NHP-Distress.

Table 4. Correlation coefficients between QoL-AGHDA and NHP sections

\begin{tabular}{lcc}
\hline & Time 1 & Time 2 \\
\hline NHP & & \\
Energy level & 0.70 & 0.72 \\
Pain & 0.43 & 0.38 \\
Emotional reactions & 0.79 & 0.81 \\
Sleep & 0.41 & 0.34 \\
Social isolation & 0.69 & 0.70 \\
Physical mobility & 0.52 & 0.46 \\
NHP-D & 0.79 & 0.79 \\
\hline
\end{tabular}

All correlations significant $p<0.01$; NHP-D: NHP-distress.

\section{Validity among known groups}

Table 5 shows the relations between QoL-AGHDA scores and self-reported general health and QoL. Higher scores were associated with poorer general health and QoL $(\mathrm{p}<0.001)$. There was no relation between the QoL-AGHDA scores and gender or age.

Table 5. QoL-AGHDA scores by perceived general health and QoL

\begin{tabular}{lcc}
\hline & $\begin{array}{c}\text { General health } \\
\text { Mean (SD) }\end{array}$ & $\begin{array}{c}\text { QoL } \\
\text { Mean (SD) }\end{array}$ \\
\hline Excellent & $5.2(3.1)$ & $6.8(6.0)$ \\
Good & $9.7(6.4)$ & $11.0(5.7)$ \\
Fair & $14.0(6.0)$ & $13.4(6.7)$ \\
Poor/very poor & $18.6(5.9)$ & $19.1(6.3)$ \\
P & $<0.001$ & $<0.001$ \\
\hline
\end{tabular}

SD: standard deviation.

\section{DISCUSSION}

The adaptation of the QoL-AGHDA for a Brazilian population, via the 4 -stage process, was successful. The measure was amenable to translation into Brazilian Portuguese and the translation was found to provide a reproducible and valid measure of the impact of GHD on the lives of affected patients.

The bilingual panel meeting progressed well and all items were translated into Brazilian Portuguese. The subsequent lay panel found the content of the translation easy to understand and decisions on its suitability were reached with little discussion. Participants in the field testing interviews agreed the content of the questionnaire was good and covered relevant aspects of patients' experience. Useful suggestions were made by the interviewees to improve the wording of certain items.

The final version of the measure was then tested psychometrically with adult GHD patients. The validation survey involved 120 patients from multiple centers who were representative of the Brazilian GHD population. These patients were similar to those enrolled for validation of the QoL-AGHDA in other countries (35,37-39). Sixty-seven point five percent (67.5\%) of the sample completed the QoL-AGHDA at both administrations. The low number of completions at Time 2 is due to the study having been stopped when a sufficient number of participants had been recruited at Time 2 for test-retest purposes. Score distributions were good with minimal levels of floor or ceiling effects. This indicates that the items are well targeted to the severity of the GHD patients.

Cronbach's alpha coefficients were above 0.9 for the QoL-AGHDA demonstrating that the items work together to form a scale. Where problems did exist, they tended to occur with single items at one time point only. The test-retest reliability of the QoL-AGHDA was excellent. The convergent validity of the measure was also supported as the results showed similar correlations to NHP sections as have been observed with other language versions of the QoL-AGHDA. The QoL-AGHDA was also able to distinguish between patients according to their perceptions of general health and QoL.

Overall the results show that the new language version of the QoL-AGHDA is conceptually equivalent to the UK-English version. When compared to other European countries, where the same adaptation methodology was applied, the results are comparable $(19,24)$. Interestingly, the median Brazilian QoL-AGHDA score was 11 , comparable to the same median score obtained for the UK, which was 10 , but higher than observed for other European countries such as Sweden, Italy, Spain, and Germany (median scores; 8, 8, 5, and 4 , respectively) (24).

The study was designed to achieve as representative a Brazilian adaptation as possible. The translated questionnaire was produced using the two-panel methodo- 
logy which is superior to a forward-backward approach in taking account cross-cultural differences between countries. Furthermore, the validation study included patients from five different regions. However, the present study was not designed to assess the responsiveness of the Brazilian QoL-AGHDA or assess its relation to other clinical factors. Future studies are needed to investigate these issues.

In conclusion, the Brazilian Portuguese version of the QoL-AGHDA is a reliable and valid measure of QoL, suitable for inclusion in clinical studies and routine clinical practice. This instrument may ultimately help clinical decision making concerning the use of $\mathrm{GH}$ therapy for adult GHD patients.

Acknowledgments: We thank the participants in the translation panels and the many patients who participated in the validation studies. The authors would also like to thank Professor John P Monson (London, UK) who first encouraged the production of the Brazilian adaptation.

Disclosure: This study was sponsored by KIMS Medical Outcomes, Pfizer Endocrine Care, Sweden. AROJr received travel grants from Pfizer; JT and SPM are employed by Galen Research Ltd which received funding from Pfizer Ltd to collaborate with the Federal University of Minas Gerais-Brazil in the adaptation of the QoL-AGHDA for use in Brazil; PACM was paid for taking a short international course on GHD; CLB is a member of the Advisory Board for Merck-Serono in Latin America regarding GHD; MKH is a permanent employee of Pfizer Health AB.

Appendix 1. QoL-AGHDA: sample items from the Brazilian Portuguese version

The full Brazilian QoL-AGHDA cannot be published herein for copyright reasons and to maintain the quality of future adaptations. People wishing to use the Brazilian Portuguese QoL-AGHDA should contact the corresponding author.

\section{Sample items:}

Eu tenho dificuldades para concluir tarefas

Eu sinto uma grande necessidade de dormir durante 0 dia

Eu frequentemente me sinto sozinho(a), mesmo quando estou com outras pessoas

Eu tenho dificuldade em controlar minhas emoções

Eu sinto falta de confiança em mim mesmo(a)

\section{REFERENCES}

1. Salomon F, Cuneo RC, Hesp R, Sonksen PH. The effects of treatment with recombinant human growth hormone on body composition and metabolism in adults with growth hormone deficiency. N Engl J Med. 1989;321(26):1797-803.

2. Hoffman DM, O'Sullivan AJ, Freund J, Ho KK. Adults with growth hormone deficiency have abnormal body composition but normal energy metabolism. J Clin Endocrinol Metab. 1995;80(1):72-7.

3. Holmes SJ, Economou G, Whitehouse RW, Adams JE, Shalet SM. Reduced bone mineral density in patients with adult onset growth hormone deficiency. J Clin Endocrinol Metab. 1994;78(3):669-74.
4. Katznelson L, Finkelstein JS, Schoenfeld DA, Rosenthal DI, Anderson EJ, Klibanski A. Increase in bone density and lean body mass during testosterone administration in men with acquired hypogonadism. J Clin Endocrinol Metab. 1996;81(12):4358-65.

5. Cuneo RC, Judd S, Wallace JD, Perry-Keene D, Burger H, Lim-Tio S, et al. The Australian Multicenter Trial of Growth Hormone (GH) Treatment in GH-Deficient Adults. J Clin Endocrinol Metab. 1998;83(1):107-16.

6. Johansson JO, Fowelin J, Landin K, Lager I, Bengtsson BA. Growth hormone-deficient adults are insulin-resistant. Metabolism. 1995;44(9):1126-9.

7. Markussis V, Beshyah SA, Fisher C, Sharp P, Nicolaides AN, Johnston DG. Detection of premature atherosclerosis by high-resolution ultrasonography in symptom-free hypopituitary adults. Lancet. 1992;340(8829):1188-92.

8. Rosen T, Eden S, Larson G, Wilhelmsen L, Bengtsson BA. Cardiovascular risk factors in adult patients with growth hormone deficiency. Acta Endocrinol (Copenh). 1993;129(3):195-200.

9. Gilchrist FJ, Murray RD, Shalet SM. The effect of long-term untreated growth hormone deficiency (GHD) and 9 years of GH replacement on the quality of life ( $\mathrm{QoL}$ ) of $\mathrm{GH}$-deficient adults. Clin Endocrinol (Oxf). 2002;57(3):363-70.

10. Mardh G, Lundin K, Borg G, Jonsson B, Lindberg A. Growth hormone replacement therapy in adult hypopituitary patients with growth hormone deficiency: combined data from 12 European placebo-controlled clinical trials. Endocrinol Metab. 1994;1(Suppl A):43-9.

11. Rosen T, Wiren L, Wilhelmsen L, Wiklund I, Bengtsson BA. Decreased psychological well-being in adult patients with growth hormone deficiency. Clin Endocrinol (Oxf). 1994;40(1):111-6.

12. Baum HB, Katznelson L, Sherman JC, Biller BM, Hayden DL, Schoenfeld DA, et al. Effects of physiological growth hormone (GH) therapy on cognition and quality of life in patients with adult-onset GH deficiency. J Clin Endocrinol Metab. 1998;83(9):3184-9.

13. Consensus Guidelines for the Diagnosis and Treatment of Adults with Growth Hormone Deficiency: Summary Statement of the Growth Hormone Research Society Workshop on Adult Growth Hormone Deficiency. J Clin Endocrinol Metab. 1998;83(2):379-1.

14. Ho KK. Consensus guidelines for the diagnosis and treatment of adults with GH deficiency II: a statement of the GH Research Society in association with the European Society for Pediatric Endocrinology, Lawson Wilkins Society, European Society of Endocrinology, Japan Endocrine Society, and Endocrine Society of Australia. Eur J Endocrinol. 2007;157(6):695-700.

15. Woodhouse LJ, Mukherjee A, Shalet SM, Ezzat S. The influence of growth hormone status on physical impairments, functional limitations, and health-related quality of life in adults. Endocr Rev. 2006;27(3):287-317.

16. Svensson J, Mattsson A, Rosen T, Wiren L, Johannsson G, Bengtsson BA, et al.Three-years of growth hormone $(\mathrm{GH})$ replacement therapy in GH-deficient adults: effects on quality of life, patient-reported outcomes and healthcare consumption. Growth Horm IGF Res. 2004;14(3):207-15.

17. Bengtsson BA, Abs R, Bennmarker $H$, Monson JP, Feldt-Rasmussen $U$, Hernberg-Stahl $E$, et al. The effects of treatment and the individual responsiveness to growth hormone $(\mathrm{GH})$ replacement therapy in $665 \mathrm{GH}$-deficient adults. KIMS Study Group and the KIMS International Board. J Clin Endocrinol Metab. 1999;84(11):3929-35.

18. Hernberg-Stahl E, Luger A, Abs R, Bengtsson BA, Feldt-Rasmussen $U$, Wilton $P$, et al. Healthcare consumption decreases in parallel with improvements in quality of life during $\mathrm{GH}$ replacement in hypopituitary adults with GH deficiency. J Clin Endocrinol Metab. 2001;86(11):5277-81.

19. Koltowska-Haggstrom M, Mattsson AF, Monson JP, Kind P, Badia X, Casanueva FF, et al. Does long-term GH replacement therapy in 
hypopituitary adults with GH deficiency normalise quality of life? Eur J Endocrinol. 2006;155(1):109-19.

20. Moock J, Albrecht $\mathrm{C}$, Friedrich $\mathrm{N}$, Volzke H, Nauck M, Koltowska-Haggstrom M, et al. Health-related quality of life and IGF-1 in $\mathrm{GH}$-deficient adult patients on $\mathrm{GH}$ replacement therapy: analysis of the German KIMS data and the Study of Health in Pomerania. Eur J Endocrinol. 2009;160(1):17-24.

21. Murray RD, Skillicorn CJ, Howell SJ, Lissett CA, Rahim A, Smethurst LE, et al. Influences on quality of life in $\mathrm{GH}$ deficient adults and their effect on response to treatment. Clin Endocrinol (Oxf). 1999;51(5):565-73.

22. Saller B, Mattsson AF, Kann PH, Koppeschaar HP, Svensson $\mathrm{J}$, Pompen $\mathrm{M}$, et al. Healthcare utilization, quality of life and patient-reported outcomes during two years of $\mathrm{GH}$ replacement therapy in $\mathrm{GH}$-deficient adults--comparison between Sweden, The Netherlands and Germany. Eur J Endocrinol. 2006;154(6):843-50.

23. Holmes SJ, McKenna SP, Doward LC, Hunt SM, Shalet SM. Development of a questionnaire to assess the quality of life of adults with growth hormone deficiency. Endocrinology and Metabolism. 1995;2:63-9.

24. McKenna SP, Doward LC, Alonso J, KohlmannT, Niero M, Prieto L, et al. The QoL-AGHDA: an instrument for the assessment of quality of life in adults with growth hormone deficiency. Qual Life Res. 1999;8(4):373-83.

25. Hunt SM, McKenna SP. The QLDS: a scale for the measurement of quality of life in depression. Health Policy. 1992;22(3):307-19.

26. Human growth hormone (somatropin) in adults with growth hormone deficiency, Technology Appraisal 64 - Guidelines of the British National Institute for Clinical Excellence. National Institute for Clinical Excellence 2003. Available from: URL: http://guidance. nice.org.uk/TA64.

27. Protocolo Clínico e Diretrizes Terapêuticas - Deficiência de Hormônio do Crescimento - Hipopituitarismo. Ministério da Saúde 2010. Available from: URL: http://www.dohms.com.br/sites_columbia/files/sempr\%203/2/pcdt_hipopituitarismo.pdf.

28. Swaine-Verdier A, Doward LC, Agell P, Horsen H, McKenna SP. Adapting quality of life instruments. Value Health. 2004;7(Suppl 1):S27-S30.
29. Hunt SM, McEwen J, McKenna SP. Measuring health status: a new tool for clinicians and epidemiologists. J R Coll Gen Pract. 1985;35(273):185-8.

30. McKenna SP, Hunt SM, Tennant A. The development of a patient completed index of distress from the Nottingham Health Profile: a new measure for use in cost-utility studies. Brit J Med Econ. 1993;6:13-24.

31. Cortina JM. What is coefficient alpha? An examination of theory and applications. J Appl Psychol. 1993;78(1):98-104.

32. Altman DG, Bland JM. Statistics Notes - Cronbach's alpha. BMJ. 1997;314(22):572.

33. McDowell. The theoretical and technical foundations of health measurements. In: Oxford: Oxford University Press, editor. Measuring health: a guide to rating scales and questionnaires. 3rd ed. New York: Oxford University Press; 2006. p. 10-54.

34. Clayton P, Gleeson H, Monson J, Popovic V, Shalet SM, Christiansen JS. Growth hormone replacement throughout life: insights into age-related responses to treatment. Growth Horm IGF Res. 2007;17(5):369-82.

35. Wiren L, Whalley D, McKenna S, Wilhelmsen L. Application of a disease-specific, quality-of-life measure (QoL-AGHDA) in growth hormone-deficient adults and a random population sample in Sweden: validation of the measure by rasch analysis. Clin Endocrinol (Oxf). 2000;52(2):143-52.

36. Clayton P, Gleeson H, Monson J, Popovic V, Shalet SM, Christiansen JS. Growth hormone replacement throughout life: insights into age-related responses to treatment. Growth Horm IGF Res 2007;17(5):369-82.

37. Koltowska-Haggstrom $M$, Kind $P$, Monson JP, Jonsson B. Growth hormone $(\mathrm{GH})$ replacement in hypopituitary adults with $\mathrm{GH}$ deficiency evaluated by a utility-weighted quality of life index: a precursor to cost-utility analysis. Clin Endocrinol (Oxf). 2008;68(1):122-9.

38. Monson JP, Jonsson P. Aspects of growth hormone $(\mathrm{GH})$ replacement in elderly patients with GH deficiency: data from KIMS. Horm Res. 2003;60(Suppl 1):112-20.

39. Clayton P, Gleeson H, Monson J, Popovic V, Shalet SM, Christiansen JS. Growth hormone replacement throughout life: insights into age-related responses to treatment. Growth Horm IGF Res. 2007;17(5):369-82. 